\title{
Prevalência de lesões osteomusculares em motoristas de ônibus: Uma revisão integrativa
}

\author{
Prevalence of musculoskeletal injuries in bus drivers: An integrative review
}

Danyele Holanda da Silva ${ }^{1 *}$, André Rodrigues Carvalho ${ }^{2}$, Rivanda Berenice Silva de Freitas Adad ${ }^{3}$, Abimael de Carvalho $^{4}$, Tassiane Maria Alves Pereira ${ }^{5}$, Izabelle Macedo de Sousa ${ }^{6}$

Como citar esse artigo. da Silva, D.H; Carvalho, A.R; Adad, R.B.S.F; de Carvalho, A; Pereira, T.M.A; de Sousa, I.M. Prevalência de lesões osteomusculares em motoristas de ônibus: Uma revisão integrativa. Revista de Saúde 2021 Abr./Jul.; 12 (2): 13-16.

\section{Resumo}

Lesões por esforços repetitivos ou distúrbios osteomusculares relacionados ao trabalho (LER / DORT) são uma síndrome que vem se tornando motivo de debate mundial, impactando o sofrimento psíquico dos trabalhadores e gerando prejuízos bilionários à sociedade.Revisão integrativa, sendorealizado o levantamento dos artigos nas bases de dados Scielo, MedLine, Lilacs, a partir da questão norteadora da busca: "Quais regiões do corpo apresentam maior prevalência de lesões musculoesqueléticas em motoristas de ônibus?". Assim, as palavras-chave: "Transtornos traumáticos cumulativos (ler / Dort)" foram cruzadas; "Saúde do trabalhador"; "Condução de veículos"; "Epidemiologia"; "Qualidade de vida". Foram encontrados 123 artigos nas bases de dados selecionadas para a busca. Após asbuscas, por meio da leitura do título e do resumo, foram selecionados 10 artigos, dos quais três artigos foram excluídos por abordarem a prevalência de lesões musculoesqueléticas em outra população que não os motoristas, restando, assim, sete artigos após leitura na íntegra que contemplava o método metodológico critérios estipulados para o desfecho pretendido, com cinco artigos em português e dois em inglês.As regiões corporais com maior prevalência de lesões osteomusculares em motoristas de ônibus foram ao longo da região do esqueleto axial, principalmente com prevalência de dor na parte superior das costas, ombros, pescoço, braços e mãos, região lombar, membros inferiores, tais como joelhos.Há elevada prevalência de lesões musculoesqueléticas em motoristas de ônibus, afetando principalmente membros superiores (ombro, pescoço, braços, punhos / mãos) seguidos de membros inferiores (joelhos) e região lombar.

Palavras-chave:Transtornos traumáticos cumulativos (LER/DORT); Saúde do trabalhador; Condução de veículo; Epidemiologia; Qualidade de vida.

\begin{abstract}
Injuries due to repetitive strain or work-related musculoskeletal disorders (RSI / WMSD) are a syndrome that has become a subject of worldwide debate, impacting the psychological suffering of workers and generating billion-dollar losses to society. Integrative review in which the survey of articles in the databases Scielo, MedLine, Lilacs was carried out, based on the guiding question of the search: "Which regions of the body have a higher prevalence of musculoskeletal injuries in bus drivers?". Thus, the keywords: "Cumulative traumatic disorders (read / Dort)" were crossed; "Worker's health"; "Driving vehicles"; "Epidemiology"; "Quality of life".A total of 123 articles were found in the databases selected for the search. After searching, by reading the title and abstract, 10 articles were selected, of which three articles were excluded because they addressed the prevalence of musculoskeletal injuries in a population other than drivers, thus leaving seven articles after reading in full that contemplated the methodological method criteria stipulated for the intended outcome, with five articles in Portuguese and two in English. The body regions with the highest prevalence of musculoskeletal injuries in bus drivers were along the region of the axial skeleton, mainly with prevalence of pain in the upper back, shoulders, neck, arms and hands, lumbar region, lower limbs, such like knees. There is a high prevalence of musculoskeletal injuries in bus drivers, mainly affecting upper limbs (shoulder, neck, arms, wrists / hands) followed by lower limbs (knees) and lower back.
\end{abstract}

Keywords: Cumulative traumatic disorders (RSI / WRMSD); Worker's health; Driving a vehicle; Epidemiology; Quality of life.

\section{Introdução}

As lesões por esforço repetitivo ou distúrbios osteomusculares relacionados ao trabalho (LER/DORT) são uma síndrome que se tornou objeto de debate mundial, que vem impactando no sofrimento psíquico dos trabalhadores e gerando prejuízos bilionários à sociedade, de acordo com revisões de literatura na área. O termo LER ainda não se consolidou como um conceito científico e nem é citado no Código Internacional das Doenças (CID-10) apesar de se apresentar como uma noção bastante utilizada no cotidiano de muitos trabalhadores e produzir um efeito significativo na descrição de sintomas musculoesqueléticos ${ }^{1}$.

Aqueles que possuem LER/DORT apresentam queixa de dor, parestesias, sensação de peso e fadiga nos membros superiores e região cervical geralmente com instalação insidiosa. Além de apresentarem também dor na região dorsolombar e nos membros inferiores. É nesse momento que se torna significativo o apoio social,

${ }^{3}$ Uninassau-Polo de saúde Redenção/ Teresina/ Piauí/ Brasil; Identificação ORCID: https://orcid.org/0000-0002-2828-64643;

${ }^{4}$ Universidade Estadual do Piauí/Teresina-Piauí/ Brasil; Identificação ORCID: https://orcid.org/0000-0002-4393-778X4;

${ }^{5}$ Universidade Federal do Piauí- UFPI/ Parnaíba/ Piauí/ Brasil; Identificação ORCID: https://orcid.org/0000-0002-8876-74385;

${ }^{6}$ Uninassau-Polo de saúde Redenção/ Teresina/ Piauí/ Brasil; Identificação ORCID:https://orcid.org/0000-0003-1406-03656

* Email de correspondência: dan_sil_holanda@hotmail.com 
de familiares, profissionais de saúde, amigos, colegas e vizinhos no auxílio da recuperação e de enfrentamento da doença ${ }^{2}$.

Existem atividades de trabalho que, devido as suas próprias demandas, implicam maior desgaste para as pessoas que as realizam como é o caso dos motoristas de ônibus urbanos, que durante o trabalho de aproximadamente 16 horas cumprem tarefas como dirigir, cobrar o custo do transporte e atender às demandas dos usuários. Essas características do processo produtivo do motorista foram descritas e classificadas por Evans \& Carrere $^{3}$ entre as mais estressantes, pois promovem a geração de condições adversas de trabalho, favorecendo o aparecimento de fatores de risco físico, químico, ergonômico e psicossocial que afetam a saúde integral desse grupo ${ }^{4}$.

No setor de transporte são conhecidos os seguintes fatores de risco: a postura estática, os movimentos repetitivos desencadeados de forma brusca e a vibração. No grupo dos fatores psicossociais foram descritas associações com altas demandas de trabalho, baixo suporte e alta exigência psicológica ${ }^{5}$.

Desta maneira, as LER/ DORT's oferecem um impacto negativo na qualidade de vida destas pessoas acometidas tornando indispensável conhecer os locais do corpo e a prevalência dessas lesões que acometem os motoristas contribuindo assim como subsídio para a prevenção de patologias secundárias e medidas preventivas a fim de oferecer um posto de trabalho mais adequado que possibilite o desempenho funcional sem prejuízo ao trabalhador e, consequentemente às empresas e/ou instituições empregadoras.

Diante disso, o objetivo desta revisão integrativa foi identificar quais regiões corporais apresentam maior prevalência de lesões osteomusculares em motoristas de ônibus.

\section{Material e Métodos}

O levantamento dos artigos foi realizado nas bases de dados: Scielo, MedLine, Lilacs, baseandose na pergunta norteadora da busca: "Quais regiões corporais apresentam maior prevalência de lesões osteomusculares em motoristas de ônibus?". Assim procedeu-se os cruzamentos das palavras-chave: "CumulativeTraumaticDisorders (Ler / Dort)"; "Worker'shealth"; "Vehicledriving"; "Epidemiology"; "Qualityoflife". As mesmas palavras-chave foram utilizadas em português.

Os critérios de Inclusão foram: estudos originais que retratassem sobre lesões osteomusculares em motoristas de ônibus, publicados nos últimos seis anos (2013- 2019). Os critérios de exclusão foram: monografias, revisões bibliográficas e sistemáticas; textos não disponíveis na íntegra, artigos que não realizaram experimentos com seres humanos. A avaliação da qualidade metodológica das produções foi realizada por meio da escala de PEDro $^{6}$.

\section{Resultados}

Foram encontrados 123 artigos nas bases de dados selecionadas para a busca, 90 artigos foram excluídos, selecionados 33 para leitura na íntegra, sendo que sete compuseram esta revisão (figura 1).

As produções incluídas foram apresentadas de acordo com a amostra (quadro 1).

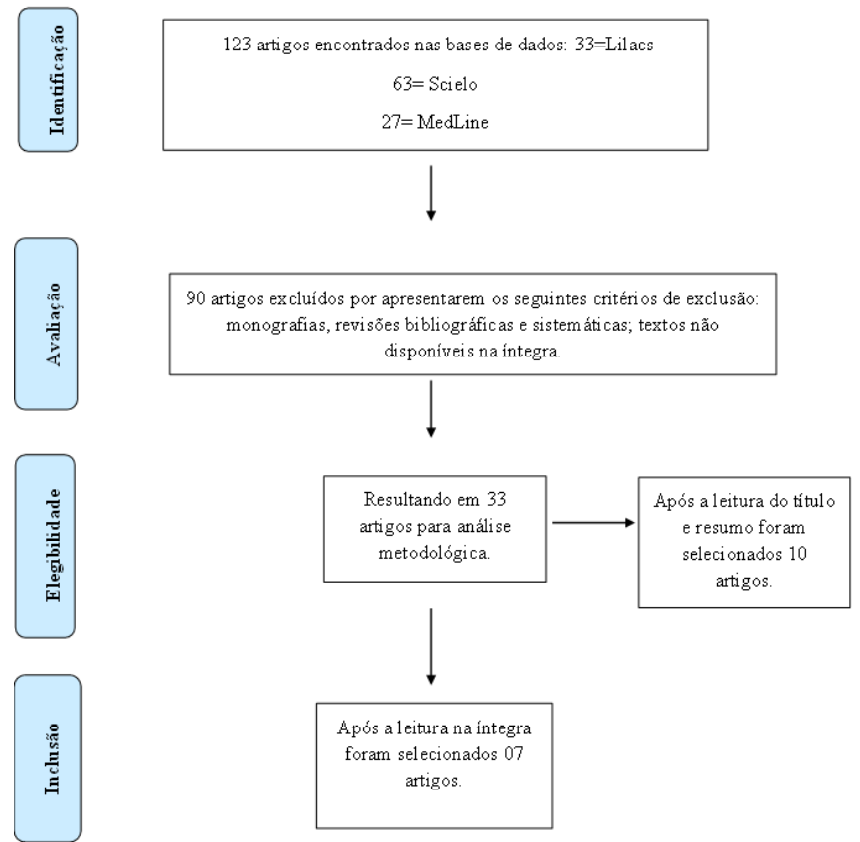

Figura 1. Fluxograma da estratégia de busca dos artigos.

\section{Discussão}

A presente revisão integrativa teve como objetivo identificar quais regiões corporais apresentam maior prevalência de lesões osteomusculares em motoristas de ônibus.

As regiões corporais que apresentaram maior prevalência de lesões osteomusculares foram ao longo da região do esqueleto axial, principalmente com prevalência de dor na parte superior das $\operatorname{costas}^{10}$, $\operatorname{ombros}^{5,7,11,12}$, pescoç ${ }^{5,7}$, braços e mãos ${ }^{5}$, região lombar $^{7,8,12}$, membros inferiores, tais como joelhos ${ }^{7,12}$.

Estudos apontaram que certas posturas adotadas pelos motoristas de ônibus, podem favorecer o aparecimento de dores, sendo a dor na região lombar 
Quadro 1. Caracterização do acervo de revisão.

\begin{tabular}{|c|c|c|c|c|c|}
\hline $\begin{array}{l}\text { AUTOR/ } \\
\text { ANO }\end{array}$ & $\begin{array}{l}\text { TIPO DE } \\
\text { ESTUDO }\end{array}$ & AMOSTRA & $\begin{array}{c}\text { TERAPÊUTICA } \\
\text { EMPREGADA }\end{array}$ & RESULTADOS OBTIDOS & $\begin{array}{l}\text { ESCALA } \\
\text { PEDRO }\end{array}$ \\
\hline 7 & $\begin{array}{l}\text { Estudo quanti- } \\
\text { tativo }\end{array}$ & 81 motoristas & $\begin{array}{l}\text { Informações sobre níveis de dor, } \\
\text { regiões dolorosas e características } \\
\text { gerais dos indivíduos; avaliação } \\
\text { ergonômica da postura; Exercício } \\
\text { de auto alongamento. }\end{array}$ & $\begin{array}{l}\text { Sintomas musculoesqueléticos estavam } \\
\text { presentes na ordem dos ombros, pesco- } \\
\text { ço, região lombar e membros inferiores. } \\
\text { Logo após a realização de auto alonga- } \\
\text { mento houve: diminuição estatistica- } \\
\text { mente significativa da dor, dos sintomas } \\
\text { osteomusculares no pescoço e ombros. }\end{array}$ & 7 \\
\hline 5 & $\begin{array}{l}\text { Estudo trans- } \\
\text { versal, descri- } \\
\text { tivo e analítico }\end{array}$ & $\begin{array}{l}799 \text { motoristas e } \\
708 \text { cobradores } \\
\text { de ônibus }\end{array}$ & $\begin{array}{l}\text { Coleta de dados através de um } \\
\text { questionário digital composto por } \\
\text { questões socioeconômicas, ocupa- } \\
\text { cionais, de saúde e hábitos de }\end{array}$ & $\begin{array}{l}\text { A prevalência de dor musculoesquelética } \\
\text { no pescoço foi de } 16,3 \% \text {. Para ombros, } \\
\text { braços e mãos foram } 15,4 \%, 13,3 \% \text { e } \\
6,3 \% \text {, respectivamente. }\end{array}$ & 6 \\
\hline 8 & $\begin{array}{l}\text { Quantitativo } \\
\text { de delinea- } \\
\text { mento trans- } \\
\text { versal }\end{array}$ & $\begin{array}{l}38 \text { motoristas e } \\
\text { cobradores }\end{array}$ & $\begin{array}{l}\text { Questionários abordando informa- } \\
\text { ções sócio demográficas e ocupa- } \\
\text { cionais dos participantes e também } \\
\text { do Questionário Nórdico de Sinto- } \\
\text { mas Osteomusculares (QNSO). }\end{array}$ & $\begin{array}{l}\text { É elevado o número de profissionais que } \\
\text { são acometidos pela sintomatologia do- } \\
\text { lorosa e que a região lombar é o princi- } \\
\text { pal sítio de acometimento. }\end{array}$ & 6 \\
\hline 9 & $\begin{array}{l}\text { Estudo obser- } \\
\text { vacional }\end{array}$ & $\begin{array}{l}1 \text { motorista, } 1 \\
\text { cobrador e uma } \\
\text { passageira. }\end{array}$ & $\begin{array}{l}\text { Procedimento de avaliação consti- } \\
\text { tuído por um conjunto de equipa- } \\
\text { mentos formado por um medidor } \\
\text { de vibração e acelerômetro tria- } \\
\text { xial, para avaliar a exposição de } \\
\text { condutores e passageiros à vibra- } \\
\text { ção de corpo-inteiro (VCI). }\end{array}$ & $\begin{array}{l}\text { Os assentos destes trabalhadores não } \\
\text { apresentam configuração apropriada, } \\
\text { pois os valores encontrados são similares } \\
\text { aos medidos nos assentos do passageiro, } \\
\text { que apresenta uma estrutura rígida. }\end{array}$ & 6 \\
\hline 10 & $\begin{array}{l}\text { Quantitativo } \\
\text { de delinea- } \\
\text { mento trans- } \\
\text { versal }\end{array}$ & 89 motoristas & QNSO & $\begin{array}{l}\text { A maior proporção de dor foi sentida ao } \\
\text { longo do esqueleto axial. A dor na parte } \\
\text { superior das costas foi a mais prevalente } \\
\text { entre os QNSO relatados nesses moto- } \\
\text { ristas. }\end{array}$ & 6 \\
\hline 11 & $\begin{array}{l}\text { Qualitativo e } \\
\text { quantitativo de } \\
\text { delineamento } \\
\text { transversal }\end{array}$ & 14 motoristas & $\begin{array}{l}\text { Questionários adaptados com a } \\
\text { finalidade de saber quais tipos de } \\
\text { Lesões osteomusculares mais pre- } \\
\text { valentes na população estudada. }\end{array}$ & $\begin{array}{l}\text { O ombro foi a região com maior presen- } \\
\text { ça de sintomas e que estes foram repre- } \\
\text { sentados com maior frequência por sen- } \\
\text { sação de queimação e dormência. }\end{array}$ & 6 \\
\hline 12 & $\begin{array}{l}\text { Estudo trans- } \\
\text { versal }\end{array}$ & 55 motoristas & $\begin{array}{l}\text { Questionário multidimensional } \\
\text { composto de variáveis demográfi- } \\
\text { cas, ocupacionais e o QNSO. }\end{array}$ & $\begin{array}{l}\text { Verificou-se que } 65,7 \% \text { dos trabalha- } \\
\text { dores relataram algum tipo de sintoma } \\
\text { osteomuscular nos últimos } 12 \text { meses, } \\
\text { localizados, principalmente, na re- } \\
\text { gião lombar }(17,0 \%) \text {, ombros e joelhos } \\
(13,3 \%) \text {. Observou-se associação entre } \\
\text { os sintomas e o baixo nível de escola- } \\
\text { ridade, a alta demanda psicológica, o } \\
\text { sedentarismo e o baixo nível de capaci- } \\
\text { dade para o trabalho. }\end{array}$ & 6 \\
\hline
\end{tabular}

como a mais desenvolvida ${ }^{8,9,12}$. É relatado que $81,9 \%$ dos motoristas de ônibus experimentam dores na região lombar e estão intimamente relacionadas às condições de trabalho e à vibração de corpo inteiro recebida do veículo e da estrada. Além disso, também foi relatado que alguns fatores como aumento da idade dos trabalhadores, tempo de trabalho e estresse psicológico estão altamente relacionados à dor lombar ${ }^{7}$.

A posição sentada assumida pelos motoristas em poltronas ergonomicamente incorretas associadas a posturas inadequadas porum longo período, movimentos repetitivos, inclinação do banco do motorista, sobrecarga na musculatura paravertebral e a obesidade estão diretamente relacionadas a dores na região lombar contribuindo para o aumento do quadro doloroso e distúrbios musculoesqueléticos incapacitantes ${ }^{12}$.

Esta dor pode ainda está associada a alterações biomecânicas causadas pelo aumento da pressão interna no núcleo do disco intervertebral, estiramento dos ligamentos, pequenas articulações e nervos, redução da circulação de retorno dos membros inferiores, tensão nos músculos isquiotibiais e glúteos (causando retroversão da pelve), horizontalização do ângulo sacral, retificação da lordose lombar e aumento das cargas compressivas 
no disco intervertebral ${ }^{12}$.

Outra dor detectada nestas pesquisas foi no ombro $^{5,7,10,11,12}$. Em motoristas, as dores nos ombros provavelmente se devem à extenuante realização de movimentos para troca de marcha e manutenção dos braços estendidos até o volante por horas seguidas exigindo constante trabalho estático e dinâmico da musculatura da cintura escapular e membros superiores $^{12}$.

Os motoristas de ônibus também possuem queixas dolorosas na região no pescoço ${ }^{5,10}$. Logo, músculos desta região participam da estabilização dos ombros durante os movimentos. A posição do ombro, por exemplo, pode aumentar substancialmente os níveis de ativação neuromuscular necessários para manter tal estabilidade. Contudo, processos dolorosos relacionados a atividade do pescoço, ombro ou membros superiores, tais como braços e mãos, potencialmente podem refletir nos demais ${ }^{5}$.

A região lombar, seguida de ombros e joelhos são focos principais da sintomatologia dolorosa neste grupo. Este dado se confirma devido à ausência de suporte ergonômico nos ônibus como assentos ajustáveis e apoio para as costas, quanto ao ombro, a exigência do ombro direito na utilização da marcha acarreta o desgaste de estruturas articulares e musculares, resultando em alguma sintomatologia dolorosa ${ }^{8}$.

A orientação e treinamento na execução de alongamentos específicos para as necessidades de cada trabalhador representam alternativas importantes que podem ser realizadas não somente nas pausas após cada término de itinerário, mas também em paradas realizadas pelos motoristas em semáforos ou para a entrada e saída de passageiros do ônibus ${ }^{11}$. A realização destes objetivos propicia uma facilidade e um melhor rendimento do trabalhado. A ergonomia analisa o posto de trabalho do motorista de ônibus urbano e juntamente com a prevenção propõe alternativas de bem-estar e conforto ao condutor ${ }^{13}$.

\section{Considerações finais}

Existem altas prevalências de lesões osteomusculares em motoristas de ônibus acometendo principalmente MMSS (ombro, pescoço, braços, punhos/ mãos) seguida de MMII (joelhos) e região lombar. Com isso, evidencia-se a importância de medidas preventivas que visem atividades de promoção a saúde, tais como: orientações sobre a postura e intervenções ergonômicas nos postos de trabalho a fim de minimizar os sintomas musculoesqueléticos e favorecer um posto de trabalho adequado e consequentemente uma melhor qualidade de vida nesta população.

\section{Referências}

1. Moraes PWT, Bastos AVB. Proposal of the instrument work-related musculoskeletal disorders index. Brazilian J Pain. 2019;2(3):266-73.

2. Silva BAM da, Silva RN da, Carlos FP, Grecco LAC, Grecco LH. Musculoskeletal employees disorders self-reported by supermarket. 2013;27(1):13-20.

3. Evans G, Carrere S. Traffic congestion, perceived control, and psychophysiological stress among urban bus drivers. J Appl Psychol. 1991;9:27-46.

4. Orozco-Solis MG, Colunga-Rodríguez C, de Lourdes PreciadoSerrano M, Ángel-González M, Vázquez-Colunga JC, Colunga-Rodríguez BA. Representação do autocuidado da saúde no trabalho de motoristas de ônibus urbano em Guadalajara, México. Cad Saúde Publica. 2017;33(3):113

5. Simões MRL, Assunção AÁ, de Medeiros AM. Musculoskeletal pain among bus drivers and fare collectors in the metropolitan region of Belo Horizonte, Brazil. Cienc e SaudeColetiva. 2018;23(5):1363-74.

6. Artioli DP, Bertolini GRF. Gua-sha: application and therapeutic results in musculoskeletal pain situations. Systematic review. Brazilian J Pain. 2019;2(3):284-8.

7. Lee JH, Gak HB. Effects of self-stretching on pain and musculoskeletal symptom of bus drivers. J Phys Ther Sci. 2014;26(12):1911-4.

8. Abreu LA, Carvalho STRF, Soares KVBC, Nacimento ALA, Sousa PHM, Gonçalves MC. Frequência de dores osteomioarticulares em profissionais do transporte público de São Luis-MA. Rev InvestigBiomédica. 2016;8(1):30.

9. Figueiredo MAM, Silva LF, Barnabé TL. Transporte coletivo: vibração de corpo-inteiro e conforto de passageiros, motoristas e cobradores. J Transp Lit. 2016;10(1):35-9.

10. Rugbeer N. The prevalence of work-related musculoskeletal disorders in longdistance bus drivers. South African J Sport Med. 2016;28(2):55-8.

11. Sérgio F, Barbosa S, Silva AP, Torres TDL. Identificação dos tipos e distribuição dos sintomas musculoesqueléticos em motoristas de ônibus para transporte coletivo municipal em Jiparaná-Rodônia. 2014;1-20.

12. De Vitta A, De Conti MHS, Trize DM, Quintino NM, Palma R, Simeão SFAP. Sintomas musculoesqueléticos em motoristas de ônibus: prevalência e fatores associados. Fisioter em Mov. 2013;26(4):863-71.

13. Amazonas RSF, Priscila D, Mejia M. 1 Propostas Ergonômicas Em Motoristas De Ônibus Urbano. 2015;1-20. 